\title{
Graphene Polymer Composites: Art of Review on Fabrication Method, Properties, and Future Perspectives
}

\author{
Niyobuhungiro Daniel ${ }^{1 *}$, Hong Liu' \\ 1 School of Mechanical Engineering, Lanzhou Jiaotong University, 730070 Lanzhou, China \\ * Corresponding author's email: danielniyobuhungiro@gmail.com
}

\begin{abstract}
Graphene has shown unique properties and introduced new challenges to light materials applicable in different areas. In addition to the polymer, it has brought materials with marvelous properties: mechanical, electrical, thermal, and related to conductivity. Different methods were discovered to produce good nanocomposites. This review summarized those methods, as well as discussed the properties of graphene combined with different kinds of polymers. Furthermore, the different factors affecting graphene reinforced polymer nanocomposites were studied. In the end, the challenges and future prospects for graphene polymer nanocomposites were considered.
\end{abstract}

Keywords: graphene, graphene polymer composites, fabrication, properties.

\section{INTRODUCTION}

Graphene as new material, due to its unique and novel properties has attracted extensive attention and in-depth research in the scientific community. Graphene, as a covalently bonded monolayer of carbon atoms with a hexagonal structure, is currently the thinnest material found in the world, and also makes it one of the world's best in terms of its properties [1]. Graphene, with this special structure, contains rich and novel physical phenomena, which make it show many excellent properties such as ultra-higqh carrier mobility, good thermal conductivity, excellent mechanical modulus (1 TPa), breaking strength $(125 \mathrm{GPa})$, and also a superior gas barrier, high transparency, and high specific surface area [2]. Moreover, based on these extraordinary properties, graphene showed great potential application prospects and market value in different fields such as transportation, high-frequency electronic devices, flexible display, electrochemical biosensor, new energy battery, supercapacitor, aerospace, biomedical, etc. Graphene can also be used as an ideal nanofiller to reinforce the properties of composites, thus providing a broader application space for composite materials. Even a small amount of graphene addition to composite tends to increase the mechanical, electrical, and processing properties [1-4]. Hence, the addition of graphene into polymer composite has shown improvements of properties compared to pure polymer, significant changes in the mechanical, electrical, and thermal properties were proven, more than in the case of other materials. The polymer nanocomposites modified by graphene can be used in construction, automobile, aerospace, electronic, and medical applications, etc. The interaction between fillers and the polymer matrix at the interface has great importance for the performance of composites $[5,6]$. As graphene is hard and very costly to produce, needs a lot of energy, and is difficult to control structure, coupled with other materials especially polymers, different alternatives were found by using modified graphene, such as graphene oxide (GO) and reduced graphene oxide (RGO) (Fig. 1), etc. provided more options which are considered easy to produce and showed a great improvement when combined with polymers. Generally, modified graphene (GO, RGO, etc) coupled with polymers and polymer composites can be possibly reached easily using various 

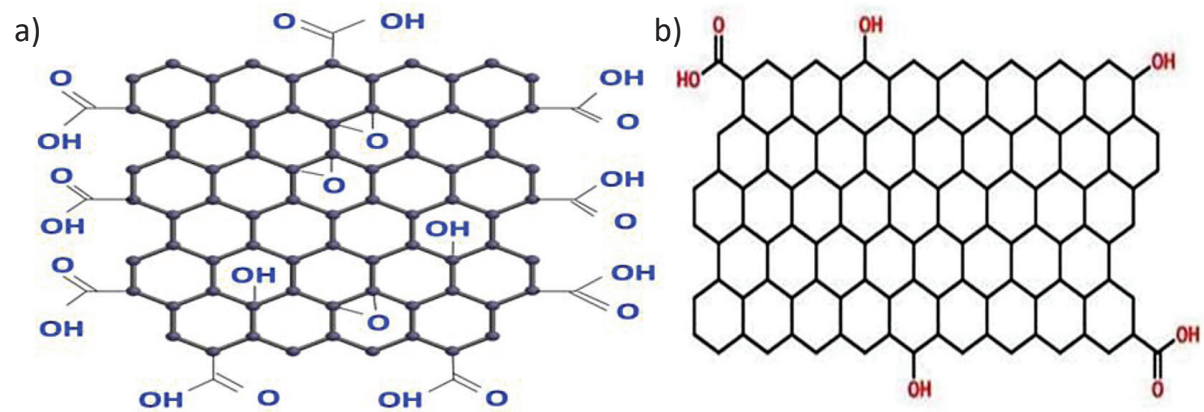

Fig 1. Modified graphene structure (a) graphene oxide, (b) reduced graphene oxide [1]

methods. Moreover, composite materials can be applied for producing materials with good tribological, electrical, and mechanical properties. Remarkably, compared with pure polymers, the addition of graphene derivatives show a great change in properties of the composite materials and proved to be suitable as alternatives to use under harsh conditions, especially corrosive and friction materials [1, 7-9]. In particular, highquality graphene nanofiller within polymer composites brought useful materials for technological applications and play a crucial benefit to the economy of different aspects. Graphene polymer composites have shown several advantages. Graphene provides new ways and opportunities for the preparation of lightweight, anti-corrosion, low friction, low-cost, high-performance, and multi-functional nanofiller/polymer composite materials $[1,2-7,10]$.

Therefore, this review studied and highlights the preparation, properties, use and applications, challenge, and future prospects for graphenebased polymer composites.

\section{PREPARATION METHODS}

The preparation methods of graphene/polymer composites mainly include solution mixing method, melt mixing method, an in-situ polymerization method [11-21]. Solution mixing involves dissolving graphene and polymer in appropriate solvent, obtaining uniform mixed solution by ultrasonic or violent stirring, and then obtaining the graphene polymer composite by removing solvent or precipitation. Solution mixing is a common method for preparing the graphene/ polymer composites. This method is simple, direct, does not require complex equipment, and can be prepared in large quantities, which can be widely used in industrial production [8, 11-13]. A variety of graphene/polymer composites were prepared by using this method, such as, polystyrene/exfoliated graphite nanoplate composites [11], polycarbonate/graphene composite [8], polyvinylpyrrolidone/zeolite composite [13], etc. Melt blending is the mixing of filler and polymer matrix at a relatively high temperature. Through strong mechanical stirring, the filler is evenly dispersed in the matrix, which enhances the interface bonding between filler and matrix. This blending method is appropriate for the mixture of thermally reduced graphene or exfoliated graphite and thermoplastic polymer. Compared with solution blending, melt blending shows a great advantage for large-scale industrial production, effectively avoiding the use of solvents, thus meeting the requirements of economy and environmental protection. Melt blending cannot achieve good spreading of fillers in the matrix like solution blending, and higher shear stress may affect the size and morphology of graphene sheets, which are connected to the properties of graphene and composite materials [14-16]. Different polymers composites were obtained with this method, including polypropylene/graphene oxide, [14] polyurethane/graphene oxide, [15] polyvinylidene fluoride/graphene [16]. In situ polymerization is a kind of polymerization method by mixing polymer monomer solution and graphene solution, adding a certain catalyst, and polymerization under appropriate conditions. It should be noted that the mixing order, proportion, and concentration of graphene and monomer solution have an important influence on the polymerization [17-21]. Some examples are polyester/reduced graphene oxide composites, [17] polyimide/graphene oxide, [18] polyurethane/graphene oxide/epoxy nanocomposites, [19] and graphene-phenol formaldehyde [20]. 


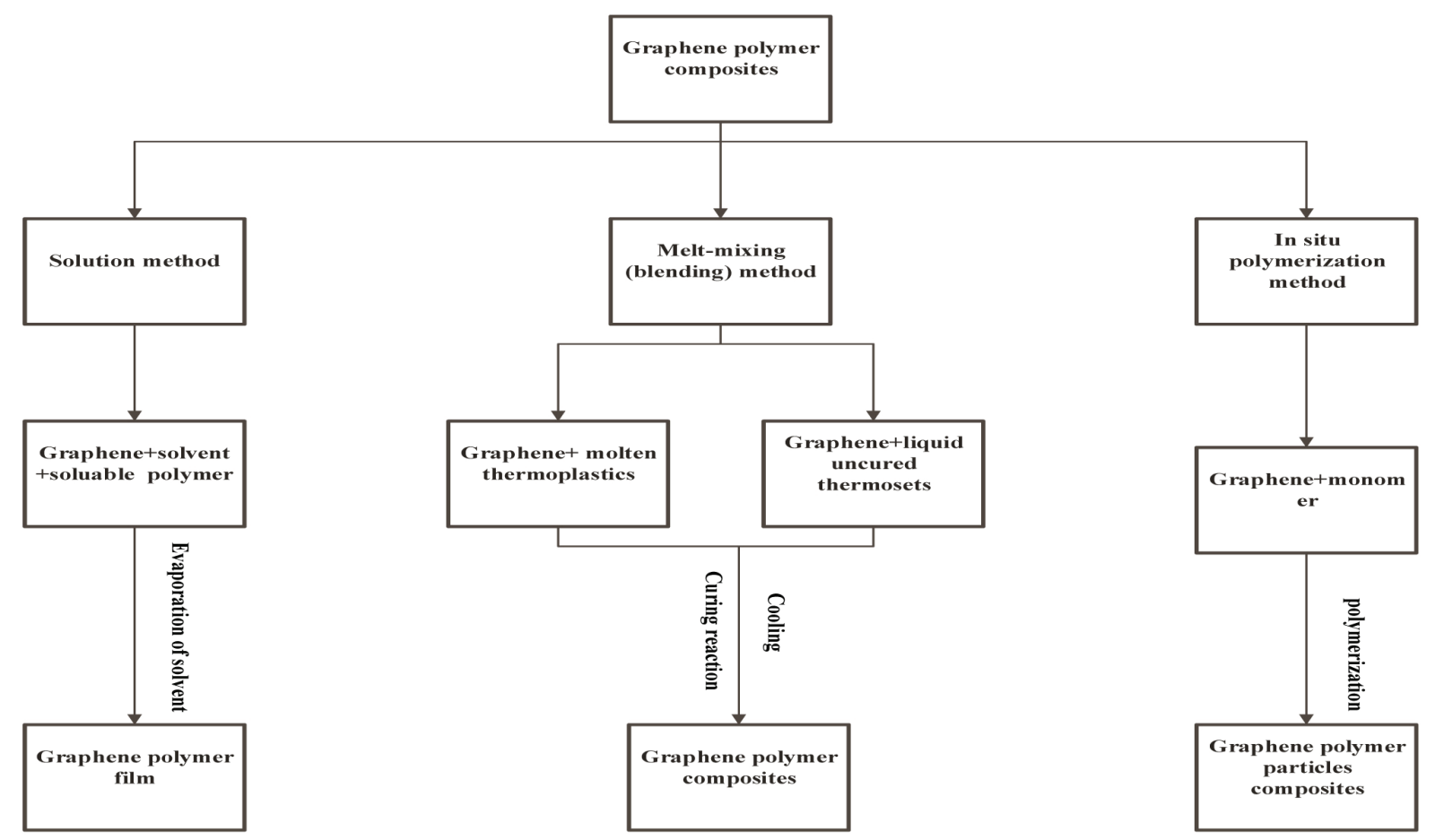

Fig. 2. Graphene/polymer composites preparation methods $[11 \div 21]$

\section{ELEMENTS INVOLVING IN THE DEVELOPMENT OF GRAPHENE INTO POLYMER NANOCOMPOSITES}

\section{Graphene structure}

Graphene is a monolayer with carbon atoms connected by sp 2 hybridization and has a honeycomb two-dimensional grid structure with a monolayer thickness of $0.35 \mathrm{~nm}$. Graphene can produce different shapes of sheets accordingly; it can be further coated into zero-dimensional fullerenes (a), curled into one-dimensional carbon nanotubes (b), and stacked into three-dimensional graphite (c), as shown in Figure 3. Nariman Yousefi et al. examined the ultra-large graphene oxide effect on nanocomposite. Hence, the lateral size of the flakes plays a significant role in controlling the microstructure and properties of graphene-based materials. Herein, reducing the size distribution of graphene sheets tends to improve the properties of macroscopic graphene materials. Different sizes of graphene nanosheets have their advantages. Large nanosheets of graphene have higher electrical conductivity compared to that of small nanosheets. [22] Graphene with ultra-small size nanolayer constitutes a novel material suitable for biological applications. Furthermore, the graphene size of nanosheets affects the electrical conductivity of nanocomposites and thermal increase proportionally with flakes size of graphene [23, 24].

\section{Preparation Methods and Mechanisms of Graphene composites}

Graphene has been commonly used to enhance the properties of polymers and has shown noteworthy results. Different methods have been used in the preparation of graphene polymer composites, as mentioned above and each has advantages well as disadvantages for the formation of final materials; for example, in the case of melt blending it is difficult to disperse graphene, and graphene oxide and some chemically modified graphene may degrade during the melting process which affects material composites. Moreover, each method has shown great enhancement properties of composites and improves the graphene polymer composites applications. Controlling graphene contents, concentration, and stability during composites formation affects the final materials where different properties can be adjusted. Selecting a suitable method also is essential for producing composites with excellent properties. Hence, the lateral size of modified graphene should be controlled and other factors such as temperature, humidity, and time duration for experiments [11-21]. 


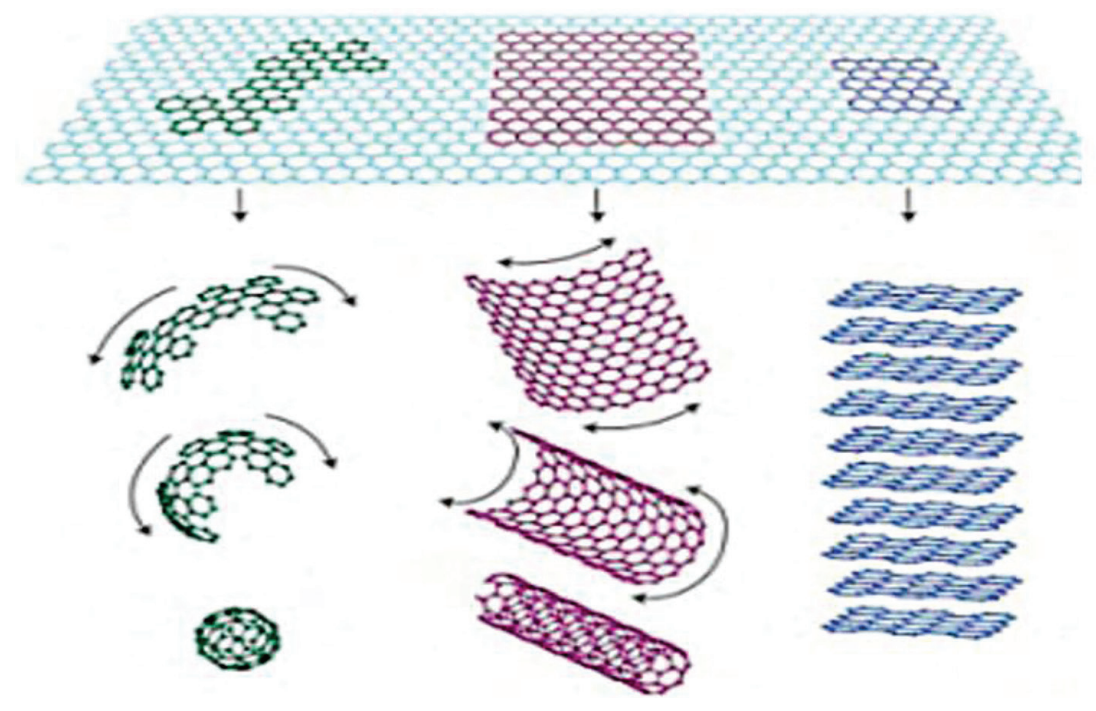

Fig. 3. Graphene structure $[25,26]$

\section{Alignment of the graphene layer into the polymer matrix}

The arrangement of graphene in polymers is somewhat related to the properties of composite materials, when the filler is arranged along the strain direction, the reinforcement is higher. Graphene showed to be a good nanofiller. Organized alignment of polymer matrices can produce improved properties, more than that of randomly graphene distribution into composites. Graphene with ultra-large nanosheets was highly aligned with polyurethane nanocomposites and showed great improvements in electrical conductivity $[27,28]$.

\section{Graphene and polymer matrix interaction}

The aggregation and orientation of graphene, the inadequate dissemination of graphene in nanocomposites, and the loss of surface layer caused by insufficient interaction between polymer and graphene will have a negative impact on the expected properties of the composites. Thence, the final product to some extent depends on the processing techniques. Moreover, aligning graphene platelets among nanocomposites should increase the Young's modulus, as compared to randomly pointed sampling. The interface structure of graphene filler and polymer composites is very important because it determined the properties of composites. Low tensile and low elongation properties of a material are caused by the poor interaction between the polymer matrix and graphene of the materials. In turn, an improved mechanical characterization of nanocomposites is a result of strong interfacial interaction [29-31].

\section{GRAPHENE-POLYMER COMPOSITES PROPERTIES}

Graphene has high elastic modulus and good electrical conductivity; these properties rendered it preferable in the preparation of new polymer composites. Graphene has a high potential for improving the properties of polymer matrix composites under very low load. The advantages of graphene polymer composites are: it improves thermal conductivity, tensile strength, electrical conductivity, wear-resistance, and elastic modulus. It is a promising multifunctional material to use in different areas [1-5, 8, 10, 32-34].

There are several types of polymers used as matrix materials, such as epoxies, phenolics, polyethylene, polypropylene, polyimide, polyester; polyurethane, etc, which show outstanding mechanical, tribological, and thermal properties.

\section{Epoxies/graphene composite materials}

Epoxy resin is a kind of high-performance thermosetting material. Some of the excellent properties of epoxy and epoxy-based materials are toughness, heat resistance, chemical resistance, adhesion, and good electrical conductivity. Therefore, they have shown a strong interest in aerospace, transportation, construction, electronic 
equipment, biomedical equipment, and so on. The addition of graphene in epoxy resin has brought a new kind of materials for the application in advanced technology $[35,36]$.

Graphene nanoplates (GNPs) have been proven to have attractive properties, while GNPs reinforced epoxy resin composites can improve their mechanical properties. Improvements in the mechanical properties of GNPs/epoxy nanocomposites are caused by a small amount of graphene nanofiller. Thermal conductivity, electrical conductivity, and thermal stability are also improved by the addition of graphene. The composite strength decreased with $0.5,1$, and 1.5 increase in $w t \%$ of GNPs. However, the modulus of the composite increased along with the amount of GNPs. With an increase in the amount of GNPs content to $1.5 \mathrm{wt} \%$, the bending modulus of the composite was the highest, i.e. increased by $19 \%$. The tensile strength of nanocomposites with $0.25 \mathrm{wt} \%$ GNPs is $20 \%$ higher than that without GNPs [37]. Wei; J. et al. studied the epoxy resin merged with different graphene contents, where nanocomposites proved to have cause favorable changes in the mechanical properties. By adding $0.3 \mathrm{wt} \%$ graphene into epoxy resin, the maximum storage modulus of nanocomposites showed an increase of $30 \%$, from $1.66 \mathrm{GPa}$ in the case of pure epoxy to $2.16 \mathrm{GPa}$. When compared to pure epoxy resin, within $0.3 \mathrm{wt} \%$ graphene nanocomposite tensile strength $12 \%$ increment was obtained (from 57.2 MPa to 64.4 MPa). Moreover, at $20^{\circ} \mathrm{C}$, the transmittance of $0.005 \mathrm{wt} \%$ graphene dispersion decreases in liquid, while the hardener increases [38]. According to the study of Burhanuddin N.I.C. et al. on the effect of graphene on epoxy resin, when the author compared the results obtained in pure epoxy resin, improvements in mechanical properties were found. The results show that the composites with different ratios of $0.5 \%, 1.0 \%$, and $1.5 \%$ show excellent reinforcement effect. After adding $0.5 \mathrm{wt} \%$ GNPs, the Young's modulus of pure epoxy resin increased from 0.675 to $8 \mathrm{GPa}$, which was $91.6 \%$ higher than that of pure epoxy resin [39]. Luo, F, et al. and $\mathrm{Yu}, \mathrm{B}$ et al. studied the graphene effect into epoxy composites and found that at low filler content of graphene composites, an important improvement of either electrical, mechanical, or thermal properties was found. Hence, graphene has shown a great adaptability for engineering applications [40, 41]. The epoxy/graphene materials mostly have very high thermal conductivity; they improve mechanical strength as well as thermal stability. The graphene reinforced epoxy nanocomposites have excellent properties and have great potential applications in automotive, electronics, aerospace, and other fields [35-41].

\section{Phenolics/graphene composite materials}

Good heat resistance and dimensional stability, high strength, and low cost are some of the advantages of phenolic resin. Phenolic resin can also contribute to the development of aerospace, transportation, and construction industries [42]. Guoping Y. et al. introduced 3D graphene into a phenolic resin composite; the mechanical and electrical properties were tested by using in situ polymerization method to produce the composites. The obtained results showed a good compressive property. Maximum compressive strength of $441.11 \mathrm{MPa}$ was obtained with $2.15 \%$ 3D graphene content, which is preferable to strong interfacial bonding between 3D graphene and the phenolics matrix material. Further increase of the graphene content, resulted in a decrease in compressive strength. Comparably, the 3D graphene/ phenolics composite showed an improvement of about $14.24 \%$ compared to neat phenolic resin. Moreover, 3D graphene showed a good electrical and thermal conductivity by introducing to phenolics resin, which increased along with the graphene content. The electrical conductivity of 3D graphene phenolics composites by the addition of $2.15 \mathrm{wt} \%$ graphene reached $2.73 \mathrm{~S} / \mathrm{cm}$ [43]. According to the study of Zhao, S., et al. on the impact of graphene addition into phenolic composites. Good mechanical, electrical, and thermal material properties were obtained as results. The $0.5 \mathrm{wt} \%$ graphene content into composite showed maximum tensile strength, where the neat phenolic resin was $34 \mathrm{MPa}$ and increase to $51.4 \mathrm{MPa}$ for phenolic resin/graphene composite. Phenolic resin combined with graphene also showed great improvement of electrical properties and the thermal conductivity of phenolic resin increased with the content of graphene [44].

Zhang, J. et al. investigated the dispersion of nanofillers which consist of graphene oxide (GO) and alkali lignin (L) at different contents, which show high improvements in material properties. GO-L comprising different ratios was introduced into the phenol-formaldehyde (PF) resin and their properties were carefully studied. With $2 \mathrm{wt} \%$, the addition of GO-L hybrids indicated that the 
storage modulus of PF increased from $2.015 \mathrm{GPa}$ to $3.675 \mathrm{GPa}$. Furthermore, during in situ curing processing, the PF/GO-L nanocomposite flow rate of heat was improved. The results provided a material with high performance [45].

\section{Polyethylene/graphene composite materials}

Nanocomposite polyethylene graphite develops the physical properties, mechanical properties, and electrical properties. Because graphene has superior physical properties and has recently been successfully isolated, it has attracted a lot of usage from its compeers. The electrical and mechanical properties of polymers like polyethylene can be improved by graphene blending [1-5, 46, 48-50].

In order to improve the properties of polyethylene (PE) such as thermal stability, crystallization, and mechanical properties, the graphene (GN) was used as the filler to different portions. Wei, P., et al., studied the highly exfoliated graphene/polyethylene composites and reported the significant improvement of yield strength, elongation at break, and impact strength of polyethylene/graphene composites. Nanofillers have a significant impact on the mechanical properties of the composites, and they are also affected by the orientation of the fillers, morphology, and the level of exfoliation of graphene [46]. Bhattacharyya et al. introduced graphene into polyethylene, the researcher findings showed that an improvement in tensile and reduction of the creep behavior of polyethylene properties can be achieved by the addition of graphene. The tensile strength of ultra-high molecular weight polyethylene (UHMWPE) was substantially enhanced by $1 \mathrm{wt} \%$ graphene oxide (go). The modulus and strength of UHMWPE increased from $864 \mathrm{MPa}$ to $1236 \mathrm{MPa}$ and from 12.6 MPa to 22.2 MPa, respectively. The creep strain of UHMWPE was reduced from $50 \%$ and reached to $9 \%$ under $40 \%$ loading for 72h [47]. Addition of graphene to low-density polyethylene (LDPE) enhances the electrical thermal and mechanical properties of LDPE/graphene nanocomposites. Graphene addition of 0.5 wt $\%$ have shown a dramatic change in LDPE/ grapheme nanocomposite, at the same time, the size of crystallite and the crate of crystallization increased compared to pure LDPE; nanocomposites have also shown ideal stability of thermal. With higher graphene content addition, the results showed increases in tensile strength, module, and yielding points of nanocomposites [48]. Pinto, F. et al, reported that the spreading of graphene in LDPE did not show any change of polymer microscopic structure, but tends to increase the stiffness and strength of nanocomposites. The 0.5 wt.\% GNP addition increased the elastic modulus of the composite, even with the increase of nanofiller content, the maximum strain of the composite decreased significantly from 5.8 to 0.33 , while the maximum stress decreases slightly from 16 to $12 \mathrm{MPa}$ [49]. Different researchers studied the polyethylene/graphene composites $[46 \div 50]$ which showed incredible properties and usefulness in modern technology of lightweight materials, aircraft parts, etc.

\section{Polypropylene/graphene composite materials}

The graphene reinforced polypropylene (PP) composites showed a beneficial impact on conductivity, thermomechanical, thermal stability, and crystallinity properties of the nanocomposites. In the dynamic mechanical analysis, the distribution of GP with different particle sizes in PP showed higher storage modulus and improved thermal stability [51]. Liang, J.Z, et al. reported that the addition of graphene into PP, showed some improvement effects of the GNPs on the flexural properties of the reinforced PP composites in GNPs weight fraction range from 0.1 to $0.5 \mathrm{wt} . \%$. The increase of GNPs mass fraction of not less than $0.4 \mathrm{wt} . \%$ improves the strength and flexural modulus of the composite [52]. Polymer composites showed the disadvantage of having poor thermal and electrical conductivity. Imran, K.A., et al. studied the improvement of electrical and thermal conductivity of polypropylene by the addition of graphene nanoplatelets. Using a coating method with the different weight ratio of graphene/polypropylene, electrical conductivity increased gradually up to $0.5 \mathrm{wt} \%$ GNP. Nevertheless, there was no change in thermal conductivity, but flexural modulus showed an increase with the addition of graphene, while the main strength and fracture strain decreased [53].

The addition of graphene nanoplatelets (GNP) in PP increased the tensile strength and decreased the elongation at break. Moreover, $\mathrm{PP} /$ graphene shows a great application in the preparation of light vehicle materials. The addition of GNP to nanocomposites makes it the best alternative for the production of polymer-based nanocomposites [54, 55]. 


\section{Graphene/polyamide composite materials}

In the case of graphene/polymer composites, polyamide (PA) has already gained great attention. Moreover, it has shown high mechanical, thermal, and electrical properties. According to the report of Nafi Yesildag, et al., concerning the properties of polyamide 6-graphene composites, the Young's modulus and tensile strength were improved by the addition of $1 \mathrm{wt} . \%$ GP to PA, as compared to pure PA [56]. A study on the effect of graphene on crystallinity, electrical and thermal properties of polyamide 6 using melting compounding method was conducted by Hoor, Farzaneh Alirezaei, et al. The results showed that the addition of graphene increased the thermal stability and electrical conductivity. By adding $1 \%$ graphene to PA6 composites, crystallinity decreased from $31.5 \%$ to $26.9 \%$ [57].

Mayoral. B. et al. reported Polyamide 6 (PA6) / graphite nanoplatelets (GNPs) composites processing and characterization using the melt-mixing method. When compared with unfilled PA6 polymer, the results showed an improvement of thermal and mechanical properties of PA6/GNPs composites. Increasing GNP content showed an improvement in crystallinity, tensile strength, and electrical conductivity of the composite [58].

Dan Zheng, et al., reported that graphene oxide introduced into PA6 using in situ polymerization $10 \mathrm{wt} . \%$ graphene oxide content in PA6 nanocomposite showed a decrease in friction coefficient and wear rate. Furthermore, the volume fraction gradually GO increased from $\sim 0.27$ to $\sim 1.09$ vol. $\%$, the electrical conductivity also quickly increased by 10 orders of magnitude from $\sim 4.2 \times 10^{-14}$ to $\sim 1.0 \times 10^{-4} \mathrm{~S} / \mathrm{m}[59]$.

\section{Graphene/polyester composite materials}

The polyester composites with GN have shown outstanding properties, Bastiurea et al., by applying a three-point bending test studied the mechanical properties of polyester composites with GN and graphite. $0.02 \mathrm{wt} \%$ and 0.1 wt $\%$ graphene showed higher yield stress, 0.02 $\mathrm{wt} \%$ graphene, and $0.1 \mathrm{wt} \%$ graphite showed the maximum value of flexural stress, and flexural strain at break, respectively, while the graphene composite showed better properties compared to graphite [60]. The graphene-based polymer nanocomposites are playing an important role in new high-performance materials with good electrical, mechanical, and thermal properties, introduced to polyester proved to strengthen the mechanical properties. Graphene nanosheets with $0.05 \%$ content improved tensile strength up to $52 \%$, and flexural strength around 92\%; furthermore, the thermal properties and the electrical properties for the nanocomposites were also improved [61]. Khan, U. et al., combining solution and melting method produced polyester filled with graphene and nanotubes. The composite showed high strength and better reinforcement; moreover as a result of the $2 \mathrm{wt} \%$ filler addition, both modulus and strength highly increased [62]. Tang, Z. et al., grafted polyester onto graphene oxide, an increased content, directly increased the thermal conductivity of the composites. By the addition of $1.45 \%$ graphene fraction volumes, the thermal conductivity of the composites showed a great increment of about $185 \%$ (from 0.19 to 0.542 $\mathrm{Wm}^{-1} \mathrm{~K}^{-1}$ ). Electrical conductivity achieved great improvement as well [63].

\section{Graphene/polyurethane}

Polyurethane has shown excellent processability, good mechanical, and electrical properties $[64,65]$. Adding graphene to polyurethane has brought a material useful in biomedical applications. Graphene content lower than $5 \mathrm{wt} \%$ significantly improves the conductivity of composites. Furthermore, composites showed excellent mechanical properties and keep the thermal properties of a pure polyurethane material [66]. Sinh, L.H., et al., using in situ polymerization method, introduced graphene into polyurethane contributing to the good improvement of properties of the composite. The addition of 0.03 $\mathrm{wt} \%$ graphene into polyurethane resulted in an improved Young's modulus and tensile strength 1.4 and 2 times, respectively. Furthermore, elongation at break remains the same while the storage modulus of polymer composite showed improvement within the high-temperature range [67]. Bahrami, S. et al., dispersed graphene into polyurethane at different concentrations. Various characteristics studied, showed that improved electrical conductivity properties of the composite can be attained by adding graphene. Moreover, the addition of $5 \mathrm{wt} \%$ graphene content can improve the mechanical properties of the composite. Therefore, it proved to be useful in biomedical applications, especially tissue engineering [68]. 


\section{APPLICATIONS}

The graphene-polymer composites proved to be suitable for the production of lightweight materials, such as gasoline tanks and plastic. They also applicable in aircraft and car parts like brakes and clutches, and also used to design strong wind turbines, anti-corrosion materials, sports equipment, medical facilities, transportation, and the electronic industry [69-71; 73].

\section{Anti-corrosion engineering}

The effect of corrosion on materials has been a great threat to the economy as well as a modern society. Different materials were affected by corrosion, which has brought a significant loss to the development of the world economy [73]. Different strategies were used for corrosion mitigation; for instance, the introduction of graphene to polymer composites coatings has shown a certain improvement [72]. Excellent properties, such as mechanical strength and low chemical reactivity are attributed to graphene, due to its ability to rapidly reduce corrosion current densities and enhance corrosion protection. Graphene has excellent mechanical strength, low chemical reactivity, applied polystyrene/graphene nanocomposites in corrosion protection. Hence, using in situ polymerization method, the polystyrene graphene nanocomposites were prepared, and found to have excellent properties for corrosion resistance. The addition of graphene has better corrosion resistance than pure polystyrene (PS), when $2 \mathrm{wt} \%$ modified GO was added into the PS polymer matrix, the anti-corrosion efficiency increased from $37.90 \%$ to $99.53 \%$ [75]. Liu, S., et al. produced graphene/epoxy coatings; the results showed that introduction of graphene improved the corrosive resistance of epoxy. The $0.5 \%$ graphene addition demonstrated better performance [76]. Meanwhile, Liu, D. et al. studied the corrosion resistance of functional graphene and fullerene C60 reinforced epoxy resin, and found that compared with pure epoxy resin, it has higher corrosion resistance. Graphene and C60 nanofiller have a good barrier effect on corrosive solution; coupled with epoxy they showed excellent physical and chemical properties which tend to improve the anti-corrosion and adhesion properties and reduce the porosity of the composite [77].

\section{Transportation}

Transportation facilitates the rapid development of the world economy, and billions of dollars have been invested in this field. Aerospace, marine transportation, and highway transportation need materials with high strength, low weight, corrosion resistance, low environmental pollution, energy-saving, and other properties. As a kind of lightweight material, the graphene integrated composites have great application potential in automobile frameworks. Graphene with a high aspect ratio, high flexibility, and mechanical strength makes it a suitable material for transportation equipment design. The introduction of graphene into polymer composites improves the properties of the composite matrix and has certain advantages in the production of vehicles. The graphene polymer composites have a stable friction coefficient and low wear rate under various working speed, pressure, temperature, surface roughness, contact stress, and environmental conditions, making them a suitable choice for transportation materials. Moreover, lightweight has been proven to be an important issue in automotive energy saving. The graphene-based polymer nanocomposites constitute materials that can reduce weight and have excellent strength. Compared with polymer composites, the properties of polymer composites with a small amount of graphene are significantly improved [40, 42, 44].

\section{Biomedical}

The nanocomposite material obtained with the composite of graphene and polymer is a new type of material with broad application prospects. Graphene nanocomposites coupled with different polymer matrices and developed by using several methods have brought advantages for use in different biomedical applications. The use of graphene with excellent properties, such as excellent thermal, mechanical, and electrical behavior, combined with different polymers, is rapidly increasing in medical implants $[1,3,78,79]$.

The applications of graphene and its derivatives in biomedicine were studied by Tonelli, F.M., et al. A small amount of graphene was added into the polymer composites to improve the mechanical strength and promote osteogenic induction, thus further promoting the growth of new bone tissue and providing an appropriate interface between natural bone and implant [79]. 


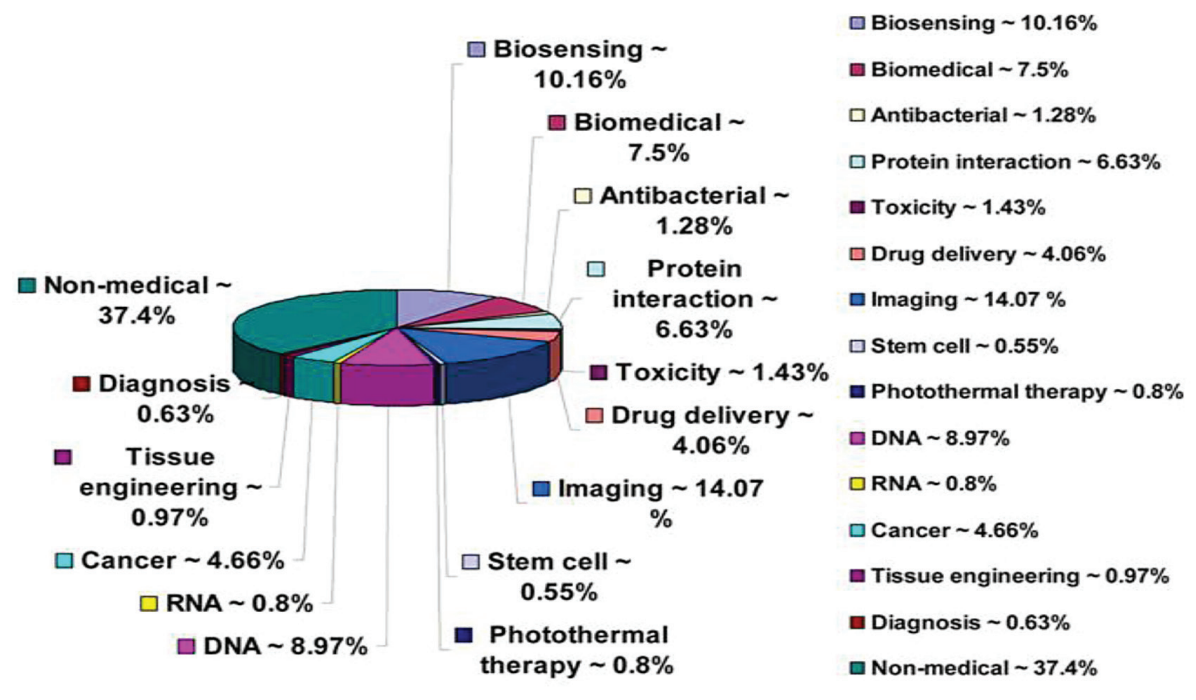

Fig. 4. Graphene-based materials applications in the field of biomedicine [84]

Seung. B.J. et al., studied the mechanical flexibility for graphene oxide grafted into polyurethane for applicable in skeletal tissue engineering. Herein, the materials with good elastic properties are very important for resisting and supporting the muscle tissue environment uncer dynamic conditions. The 8 wt.\% graphene addition introduced to composite showed a great increase of elasticity as well as good stress relaxation properties and hydrophilicity [80]. In biomedicine, graphene incorporated into with polymer plays a great role in different biomedical aspects (Fig 4). Biosensing materials for monitoring and diagnosis of various diseases need to have excellent properties. Graphene has shown remarkable properties when grafted with polymers, providing ideal composite support for the development of biosensors [81].

A bacterial infection is a world problem for human life, graphene nanocomposite solutions, combining polymer and graphene offers ideal materials for antibacterial applications [82]. Therefore, graphene polymer composites have shown great progress in the fields of antibacterial, drug delivery, biosensor, bioelectronics, cancer treatment, and tissue engineering [83].

\section{Electronic industry}

Graphene filled polymers play an important role in the manufacturing of sensors, capacitors, shielding, and many other electronic and mechanical devices. Graphene polymer nanocomposites exhibit excellent properties in transistors, electroluminescent devices, batteries, memory devices, gate dielectrics, light-emitting diodes, and touch screen devices [85]. Mainly coupled polymer/graphene nanocomposite has found success for sensor applications. Polymer/graphene has also been used to construct large flexible panels in solar cells and also in fuel cell structure $[4,6]$. Additionally, these hybrid materials have shown fabrication possibilities for supercapacitors, optical displays, printing circuits, electrical devices, photo- and superconductor devices [69].

An essential use of polymer/graphene has also been observed in the thermal management of electronics or electronic devices such as cell phones, laptops, LEDs, etc. In short, the polymer/graphene nanocomposites have started a new era of research and countless possibilities for electronic devices and systems and the overall electronics industry [86].

\section{CONCLUSION AND FUTURE PERSPECTIVES}

Polymer composites are useful in different aspects of the human life. However, the interface bonding effect is not ideal. Traditional composite materials cannot meet the growing needs of people. Graphene has a unique hexagonal network plane structure as well as excellent physical, mechanical, and chemical properties. It is an ideal inorganic filler. Graphene is functionalized and then compounded with a polymer matrix to obtain materials with excellent properties (mechanical, thermal, etc.) 
This article reviewed graphene polymer processing, properties, and applications. It comparatively showed excellent properties and choices for the development of new materials applied under harsh conditions such as high speed, temperature variations, and effectively for environment protection. Nevertheless, challenges still exist, for example:

- Technical barriers, including structure control, matrix dispersion of graphene, interfacial interaction of graphene and composite matrix, and individual contact of graphene.

- Quality in mass production of graphene.

- Producing good quality, low cost with large quantity, and regulated structure of graphene is still a difficult problem in large-scale polymer composites production.

- Characteristics of graphene polymer composites depend strongly on the graphene distribution in the polymer matrices. Better dispersion of graphene in polymers is also a fundamental problem for advanced applications.

Although different challenges exist, graphene polymer composites show great future perspectives in different domains of life. The dispersion of a small amount of graphene in the polymer has demonstrated that the design of materials with good properties can successfully be achieved. The outstanding properties of graphene grafted into polymer are important in electronic devices, which is expected to replace silicon in optical transparency, computer chips, or ultraviolet nitride light-emitting diode. They also showed excellent mechanical properties, which could be applied to produce automotive components, medical facilities, energy storage equipment, and more others.

\section{Acknowledgments}

The authors thank the financial support from Lanzhou Jiaotong University.

\section{REFERENCES}

1. Tiwari, S.K., Sahoo, S., Nannan Wang, \& Huczko, A. Graphene research and their outputs: Status and Prospect. Journal of Science: Advanced Materials and Devices. 2020.

2. Loh, K.P., Bao, Q., Ang, P.K., \& Yang, J. The chemistry of graphene. Journal of Materials Chemistry, 2010, 20(12), 2277.
3. Yang, G., Li, L., Lee, W.B., \& Ng, M.C. Structure of graphene and its disorders: a review. Science and Technology of Advanced Materials, 2018, 19(1), 613-648.

4. Tjong, S. C. Polymer Composites with Graphene Nanofillers: Electrical Properties and Applications. Journal of Nanoscience and Nanotechnology, 2014, 14(2), 1154-1168.

5. Kim, H., Abdala, A.A., \& Macosko, C.W. Graphene/Polymer Nanocomposites Macromolecules, 2010, 43(16), 6515-6530.

6. Kumar, A., Sharma, K., \& Dixit, A. R., A review of the mechanical and thermal properties of graphene and its hybrid polymer nanocomposites for structural applications. Journal of Materials Science, 2018.

7. Sanes, Sánchez, Pamies, Avilés, \& Bermúdez. Extrusion of Polymer Nanocomposites with Graphene and Graphene Derivative Nanofillers: An Overview of Recent Developments. Materials, 2020, 13(3), 549.

8. Lago, E.; Toth, P.S.; Pugliese, G.; Pellegrini, V.; Bonaccorso, F. Solution blending preparation of polycarbonate/graphene composite: Boosting the mechanical and electrical properties. RSC Adv. 2016, 6, 97931-97940.

9. Galpaya, D., Wang, M., Liu, M., Motta, N., Waclawik, E., \& Yan, C. Recent Advances in Fabrication and Characterization of Graphene-Polymer Nanocomposites. Graphene, 2012. 01(02), 30-49.

10. Noh, Y., Joh, H., Yu, J. et al. Ultra-high dispersion of graphene in polymer composite via solvent-free fabrication and functionalization. Sci Rep 2015. 5, 9141.

11. He, F.; Lam, K.-H.; Fan, J.; Chan, L.H. Improved dielectric properties for chemically functionalized exfoliated graphite nanoplates/syndiotactic polystyrene composites prepared by a solution-blending method. Carbon 2014, 80, 496-503.

12. Liang, A., Jiang, X., Hong, X., Jiang, Y., Shao, Z., \& Zhu, D. Recent Developments Concerning the Dispersion Methods and Mechanisms of Graphene. Coatings, 2018, 8(1), 33.

13. Alver, E.; Metin, A.Ü.; Çiftçi, H. Synthesis and characterization of chitosan/ polyvinylpyrrolidone/ zeolite composite by solution blending method. J. Inorg. Organomet. Polym. Mater. 2014, 24, 1048-1054.

14. Yun, Y.S., Bae, Y.H., Kim, D.H., Lee, J.Y., Chin, I.J., Jin, H.J., Reinforcing effects of adding alkylated graphene oxide to polypropylene. Carbon, 2011, 49, 3553-3559.

15. Yousefi, N., Gudarzi, M.M., Zheng, Q., Lin, X., Shen, X., Jia, J., Sharif, F., Kim, J.-K., Highly aligned, ultra-large-size reduced graphene oxide/polyurethane nanocomposites: Mechanical properties and moisture permeability. Composites Part A: Applied Science and Manufacturing. 2013a, 49, 42-50. 
16. Shang, J., Zhang, Y., Yu, L., Luan, X., Shen, B., Zhang, Z., Lv, F., Chu, P.K., Fabrication and enhanced dielectric properties of graphene-polyvinylidene fluoride functional hybrid films with a polyaniline interlayer. Journal of Materials Chemistry, 2013. A1, 884.

17. Liu, K., Chen, L., Chen, Y., Wu, J., Zhang, W., Chen, F., Fu, Q., Preparation of polyester/reduced graphene oxide composites via in situ melt polycondensation and simultaneous term reduction of graphene oxide. Journal of Materials Chemistry, 2011. 21, 8612-8617.

18. Wang, J.-Y., Yang, S.-Y., Huang, Y.-L., Tien, H.-W., Chin, W.-K., Ma, C.-C.M., Preparation and properties of graphene oxide/polyimide composite films with low dielectric constant and ultrahigh strength via in situ polymerization. Journal of Materials Chemistry, 2011b, 21, 13569.

19. Li, Y., Pan, D., Chen, S., Wang, Q., Pan, G., Wang, T., In situ polymerization and mechanical, thermal properties of polyurethane/graphene oxide/epoxy nanocomposites. Materials \& Design 47, 850-856.

20.Zhao, X., Li, Y., Wang, J., Ouyang, Z., Li, J., Wei, G., Su, Z., 2014. The interactive oxidationreduction reaction for the in situ synthesis of graphene-phenol formaldehyde composites with enhanced properties. ACS Appl Mater Interfaces 6, 4254-4263.

21. Guo, F., Aryana, S., Han, Y., \& Jiao, Y. A Review of the Synthesis and Applications of Polymer-Nanoclay Composites. Applied Sciences, 2018. 8(9), 1696.

22. Yousefi N., Gudarzi M.M., Zheng Q., et al. Selfalignment and high electrical conductivity of ultra-large graphene oxide-polyurethane nanocomposites J. Journal of Materials Chemistry, 2012, 22(25): 12709-12717.

23. Liu Z, Robinson J.T., Sun X, et al. PEGylated nanographene oxide for delivery of water-insoluble cancer drugs J. Journal of the American Chemical Society, 2008, 130(33): 10876-10877

24. Ghosh S., Bao W., Nika D.L., et al. Dimensional crossover of thermal transport in few-layer graphene J. Nature materials, 2010, 9(7): 555-558.

25. Geim, A.K., \& Novoselov, K.S. The rise of graphene. Nature Materials, 2007, 6(3), 183-191.

26. Neto, A.C., Guinea, F., \& Peres, N.M. Drawing conclusions from graphene. Physics World, 2006, 19(11), 33-37.

27. Papageorgiou, D.G., Li, Z., Liu, M., Kinloch, I.A., \& Young, R.J. Mechanisms of mechanical reinforcement by graphene and carbon nanotubes in polymer nanocomposites. Nanoscale. 2020.

28. Shi, J., Yang, J., Zhou, J., Ji, H., Tang, X., \& Gao, T. Effect of graphene on thermal stability and mechanical properties of ethylene-vinyl acetate:
A molecular dynamics simulation. Materials Research Express. 2020.

29. Dickinson, L.R., Kranbuehl, D.E., \& Schniepp, H.C. Assessing graphene oxide/polymer interfacial interactions by way of peeling test. Surface Innovations, 2016, 4(3), 158-166.

30. Feng, J., Venna, S.R., \& Hopkinson, D. P. Interactions at the interface of polymer matrix-filler particle composites. Polymer, 2016, 103, 189-195.

31. Chee, W.K., Lim, H.N., Huang, N.M., \& Harrison, I. Nanocomposites of graphene/polymers: a review. RSC Advances, 2015, 5(83), 68014-68051.

32. Du, J., \& Cheng, H.-M. The Fabrication, Properties, and Uses of Graphene/Polymer Composites. Macromolecular Chemistry and Physics, 2012, 213(10-11), 1060-1077.

33. Verma, D., Gope, P.C., Shandilya, A., \& Gupta, A. Mechanical-Thermal-Electrical and Morphological Properties of Graphene Reinforced Polymer Composites: A Review. Transactions of the Indian Institute of Metals, 2014, 67(6), 803-816.

34. Johnson, D.W., Dobson, B.P., \& Coleman, K.S. A manufacturing perspective on graphene dispersions. Current Opinion in Colloid \& Interface Science, 2015, 20(5-6), 367-382.

35 . Inam, F. Epoxy - the hub for the most versatile polymer with an exceptional combination of superlative features. Epoxy, 2014, 1(1).

36. Wei, J., Vo, T., \& Inam, F. Epoxy/graphene nanocomposites - processing and properties: a review. RSC Advances, 2015, 5(90), 73510-73524.

37. Shen, M.-Y., Chang, T.-Y., Hsieh, T.-H., Li, Y.-L., Chiang, C.-L., Yang, H., \& Yip, M.-C. Mechanical Properties and Tensile Fatigue of Graphene Nanoplatelets Reinforced Polymer Nanocomposites. Journal of Nanomaterials, 2013, 1-9.

38. Wei, J., Atif, R., Vo, T., \& Inam, F. Graphene Nanoplatelets in Epoxy System: Dispersion, Reaggregation, and Mechanical Properties of Nanocomposites. Journal of Nanomaterials, 2015, 1-12.

39. Berhanuddin, N.I.C., Zaman, I., Rozlan, S.A.M., Karim, M.A.A., Manshoor, B., Khalid, A., Meng, Q. Enhancement of mechanical properties of epoxy/graphene nanocomposite. Journal of Physics: Conference Series, 2017, 914, 012036.

40. Luo, F.; Wu, K.; Guo, H.; Zhao, Q.; Lu, M. Simultaneous Reduction and Surface Functionalization of Graphene Oxide for Enhancing Flame Retardancy and Thermal Conductivity of Mesogenic Epoxy Composites. Polym. Int. 2017, 66, 98-107.

41. Yu, B.; Shi, Y.; Yuan, B.; Qiu, S.; Xing, W.; Hu, W.; Song, L.; Lo, S.; Hu, Y. Enhanced Thermal and Flame Retardant Properties of Flame-RetardantWrapped Graphene/Epoxy Resin Nanocomposites. J. Mater. Chem. A. 2015, 3, 8034-8044. 
42. Xu, Y., Guo, L., Zhang, H., Zhai, H., \& Ren, H. Research status, industrial application demand, and prospects of phenolic resin. RSC Advances, 2019, 9(50), 28924-28935.

43. Yang, G., Wang, Y., Zhou, S., Jia, S., Xu, H., \& Zang, J. Graphene/phenolic resin-based porous carbon composites with improved conductivity prepared via in situ polymerization in graphene hydrogels. Journal of Materials Science. 2018.

44. Zhao, S., Cui, J., Zhang, G., Gao, A., \& Yan, Y. An alternative avenue for high-performance phenolic resin/graphene composite. Polymer Composites. 2019.

45. Zhang, J., Rumin, W., \& Chen, P. Reinforcing of phenol-formaldehyde resin by graphene oxide and lignin nanohybrids. High-Performance Polymers, 2019.

46. Wei, P., \& Bai, S. Fabrication of a high-density polyethylene/graphene composite with high exfoliation and high mechanical performance via solidstate shear milling. RSC Advances, 2015, 5(114), 93697-93705.

47. Bhattacharyya, A., Chen, S., \& Zhu, M. Graphene reinforced ultra-high molecular weight polyethylene with improved tensile strength and creep resistance properties. Express Polymer Letters, (2014), 8, 74-84.

48. Sabet, M., Soleimani, H., \& Hosseini, S. Graphene impact of the LDPE characteristics. Polymer Bulletin. 2019.

49. Pinto, F., Carotenuto, G., \& Meo, M. Preparation and thermomechanical characterization of graphene nanoplatelets/low-density polyethylene composites. Journal of Thermoplastic Composite Materials, 2013, 28(6), 745-761.

50. Seo, H.M., Park, J.H., Dao, T.D., \& Jeong, H. M. Compatibility of Functionalized Graphene with Polyethylene and Its Copolymers. Journal of Nanomaterials, 2013, 1-8.

51. Ajorloo, M., Fasihi, M., Ohshima, M., \& Taki, K. How are the thermal properties of polypropylene/ graphene nanoplatelet composites affected by polymer chain configuration and size of nanofiller. Materials \& Design, 2019, 108068.

52. Liang, J.Z., \& Du, Q. Melt Flow and Flexural Properties of Polypropylene Composites Reinforced with Graphene Nano-Platelets. International Polymer Processing, 2018, 33(1), 35-41.

53. Imran, K.A., Lou, J., \& Shivakumar, K. N. Enhancement of electrical and thermal conductivity of polypropylene by graphene nanoplatelets. Journal of Applied Polymer Science, 2017,135(9), 45833.

54. Al-Saleh, M.A.; Yussuf, A.A.; Al-Enezi, S.; Kazemi, R.; Wahit, M.U.; Al-Shammari, T.; Al-Banna, A.Polypropylene/Graphene Nanocomposites: Effects of GNP Loading and Compatibilizers on the Mechanical and Thermal Properties. Materials, 2019, 12, 3924.
55. Bafana, A.P., Yan, X., Wei, X., Patel, M., Guo, Z., Wei, S., \& Wujcik, E.K. Polypropylene nanocomposites reinforced with low weight percent graphene nanoplatelets. Composites Part B: Engineering, 2017, 109, 101-107.

56. Yesildag, N., Hopmann, C., Adamy, M., \& Windeck, C. Properties of polyamide 6-graphene-composites produced and processed on an industrial scale. 2017.

57. Alirezaei Hoor, F., Morshedian, J., Ahmadi, S., Rakhshanfar, M., \& Bahramzadeh, A. Effect of Graphene Nanosheets on the Morphology, Crystallinity, and Thermal and Electrical Properties of Super Tough Polyamide 6 Using SEBS Compounds. Journal of Chemistry, 2015, 1-6.

58. Mayoral, B., Harkin-Jones, E., Khanam, P. N., AlMaadeed, M.A., Ouederni, M., Hamilton, A., \& Sun, D. Melt Processing and Properties of Polyamide 6/Graphene Nanoplatelet Composites. In Proceedings of the 20th International Conference on Composite Materials ICCCM. 2015.

59. Zheng, D.; Tang, G.; Zhang, H. B.; Yu, Z.Z.; Yavari, F.; Koratkar, N.; Lim, S.H.; Lee, M.W. In Situ Thermal Reduction of Graphene Oxide for High Electrical Conductivity and Low Percolation Threshold in Polyamide 6 Nanocomposites. Compos. PolymerPlastics Technology and Materials 13 Sci. Technol. 2012, 72, 284-289.

60. Bastiurea, M., Rodeanu, M.S., Dima, D., Murarescu, M., \& Andrei, G. Evaluation of Mechanical Properties of Polyester Composite with Graphene and Graphite through Three-Point Bending Test. Applied Mechanics and Materials, 2014, 659, 22-27.

61. Swain, S. Synthesis and Characterization of Graphene-Based Unsaturated Polyester Resin Composites. Transactions on Electrical and Electronic Materials, 2013, 14(2), 53-58.

62. Khan, U., Young, K., O’Neill, A., \& Coleman, J. $N$. High strength composite fibers from polyester filled with nanotubes and graphene. Journal of Materials Chemistry, 2012, 22(25), 12907.

63. Tang, Z., Kang, H., Shen, Z., Guo, B., Zhang, L., \& Jia, D. Grafting of Polyester onto Graphene for Electrically and Thermally Conductive Composites. Macromolecules, 2012, 45(8), 3444-3451.

64. S. Gogolewski, Colloid. Polym. Sci., 1989, 267, 757-785.

65. M. S. Kathalewar, P.B. Joshi, A. S. Sabnis and V.C. Malshe, RSC Adv., 2013, 3, 4110-4129

66. Kaur, G., Adhikari, R., Cass, P., Bown, M., Evans, M.D.M., Vashi, A.V., \& Gunatillake, P. Graphene/ polyurethane composites: fabrication and evaluation of electrical conductivity, mechanical properties, and cell viability. RSC Advances, 2015, 5(120), 98762-98772. 
67. Sinh, L.H., Luong, N.D., \& Seppälä, J. Enhanced mechanical and thermal properties of polyurethane/ functionalized graphene oxide composites by in situ polymerization. Plastics, Rubber, and Composites, 2019. 1-11.

68. Bahrami, S., Solouk, A., Mirzadeh, H., \& Seifalian, A.M. Electroconductive polyurethane/graphene nanocomposite for biomedical applications. Composites Part B-engineering, 2019, 168, 421-431.

69. Das, T.K., \& Prusty, S. Graphene-Based Polymer Composites and Their Applications. Polymer-Plastics Technology and Engineering, 2013, 52(4), 319331.

70. Bhavana M. Itapu1 and Ahalapatiya H. Jayatissa.. A Review in Graphene/Polymer Composites. Chemical Science International Journal, 2018, 23(3): 1-16.

71. Sangaj, N.S., \& Malshe, V. C. Permeability of polymers in protective organic coatings. Progress in Organic Coatings, 2004, 50(1), 28-39.

72. Othman, N.H., Che Ismail, M., Mustapha, M., Sallih, N., Kee, K.E., \& Ahmad Jaal, R. Graphenebased polymer nanocomposites as barrier coatings for corrosion protection. Progress in Organic Coatings, 2019, 135, 82-99.

73. D. Galpaya, M. Wang, M. Liu, N. Motta, E. Waclawik, and C. Yan. Recent Advances in Fabrication and Characterization of Graphene-Polymer Nanocomposites, Graphene, 2012, Vol. 1 No. 2, pp. 30-49.

74. Qi, K., Sun, Y., Duan, H., \& Guo, X. A corrosionprotective coating based on a solution-processable polymer-grafted graphene oxide nanocomposite. Corrosion Science, 2015, 98, 500-506.

75. Yu, Y.-H., Lin, Y.-Y., Lin, C.-H., Chan, C.-C., \& Huang, Y.-C. High-performance polystyrene/ graphene-based nanocomposites with excellent anti-corrosion properties. Polym. Chem., 2014, 5(2), 535-550.

76. Liu, S., Gu, L., Zhao, H., Chen, J., \& Yu, H. Corrosion Resistance of Graphene-Reinforced Waterborne Epoxy Coatings. Journal of Materials Science \& Technology, 2016, 32(5), 425-431.
77. Liu, D., Zhao, W., Liu, S., Cen, Q., \& Xue, Q. Comparative tribological and corrosion resistance properties of epoxy composite coatings reinforced with functionalized fullerene C60 and graphene. Surface and Coatings Technology, 2016, 286, 354-364.

78. Teo, A. J.T., Mishra, A., Park, I., Kim, Y.-J., Park, W.-T., \& Yoon, Y.-J. Polymeric Biomaterials for Medical Implants and Devices. ACS Biomaterials Science \& Engineering, 2016, 2(4), 454-472.

79. Tonelli, F.M., Goulart, V.A., Gomes, K.N., Ladeira, M.S., Santos, A.K., Lorençon, E., Resende, R.R. Graphene-based nanomaterials: biological and medical applications and toxicity. Nanomedicine, 2015, 10(15), 2423-2450.

80. Jo, S.B., Erdenebileg, U., Dashnyam, K., Jin, G.Z., Cha, J.R., El-Fiqi, A., Knowles, J.C., Patel, K.D., Lee, H.H., Lee, J.H., \& Kim, H.W. Nano-graphene oxide/polyurethane nanofibers: mechanically flexible and myogenic stimulating matrix for skeletal tissue engineering. Journal of tissue engineering, 2020, 11, 2041731419900424.

81. Dey, R.S. Development of Biosensors from Polymer Graphene Composites. Graphene-Based Polymer Nanocomposites in Electronics, (2015), 277-305.

82. Khandelwal, G., Kumar, R., \& Kumar, V. Antimicrobial Activities of Graphene-Polymer Nanocomposites. Nanostructured Polymer Composites for Biomedical Applications, 2019, 429-445.

83. Silva, M., Alves, N. M., \& Paiva, M. C. Graphenepolymer nanocomposites for biomedical applications. Polymers for Advanced Technologies, 2017, 29(2), 687-700.

84. Mao, H.Y., Laurent, S., Chen, W., Akhavan, O., Imani, M., Ashkarran, A.A., \& Mahmoudi, M. Graphene: Promises, Facts, Opportunities, and Challenges in Nanomedicine. Chemical Reviews, 2013, 113(5), 3407-3424.

85. Tyagi M, Tyagi D. Polymer Nanocomposites and their Applications in Electronics Industry. Int J Electron Electr Eng. 2014.7:603-630

86. Sadasivuni, K.K., Ponnamma, D., Kim, J., \& Thomas, S. (Eds.). Graphene-Based Polymer Nanocomposites in Electronics. 2015. 